\title{
NOVAS EVIDÊNCIAS DE MAGMATISMO ALCALINO NA REGIÃO DA BAÍA DE GUANABARA (RIO DE JANEIRO)
}

\author{
M.L.S.C.Chaves ${ }^{1}$; C.R.Martins' ${ }^{2}$, I.A.Dossin'
}

PALAVRAS-CHAVE: rocha alcalina, barita, Baia de Guanabara, magmatismo cenozóico.

CHAVES, M.L.S.C. et al. (1993) Novas evidências de magmatismo alcalino na regiăo da Baia de Guanabara (Rio de Janeiro), Bol.IG-USP, Sér.Cient, 24:43-47.

\section{RESUMO}

Embora, em termos de dimensões, correspondam a ocorrências pontuais, duas novas evidências de magmatismo alcalino, provavelmente tardi-cretácico ou cenozóico, são descritas na região da Baia de Guanabara, Estado do Rio de Janeiro. A brecha alcalina da tha de Jurubaiba possui matriz fonolitica com fragmentos de traquito, nefelina fonolito e nefelina sienito. A ocorrência de barita da liha do Governador encontra-se em um veio de calcedônia brechada e sua origem deu-se a partir de fluidos hidrotermais. provavelmente relacionados ao mesmo magmatismo alcalino. As ocorrências descritas podem estar associadas a falhas normais que se formaram durante a separaçăo continental América do Sul/África.

\begin{abstract}
New evidence of alkaline magmatism, probably of late Cretaceous-Cenozoic age, is described from Guanabara Bay. State of Rio de Janeiro. It is represented by rock occurrences covering very small areas. The alkaline breccia of Jurubaiba Island has a phonolitic matrix with trachyte, phonolite and nepheline syenite pyroclasts. Barite of Governador Island occurs in a chalcedony breccia vein and its genesis is related to hydrothermal fluids of the same alkaline magmatic event. These occurrences are thought to be associated with normal faulting during the separation of South America and Africa.
\end{abstract}

\section{INTRODUÇÃo}

Desde que Derby (1887) fez alusão a foiaítos, brechas vulcânicas e tufos fonoliticos na Serra do Tinguá (Nova IguaçúRJ), inúmeras outras ocorrências de rochas alcalinas, além de certas mineralizaçōes associadas (fluorita, barita, coríndon, etc.),

\footnotetext{
1'Departamento de Geologia, IGCANMG, Belo Horizonte, Brasil. ${ }^{2}$ Departamento de Recursos Minerais, Niterói, Brasil
}

têm sido descritas na região Sul-Fluminense. Este trabalho objetiva as descrições de uma nova ocorrência de rocha alcalina e de um veio mineralizado em barita, considerado indiretamente relacionado ao mesmo evento magmático, descobertos na área da 
Baía de Guanabara.

A rocha alcalina foi localizada próximo à Ilha de Jurubaiba, em 1980, durante reconhecimento geológico efetuado por um dos autores (CRM). O achado foi preliminarmente comunicado por Martins \& Borghi (1982). O presente estudo, visando a caracterização dessa rocha, se justifica por ser a primeira ocorrência de rocha alcalina situada no interior da Baía de Guanabara, a partir de material coletado em nova visita à ocorrência.

A barita da Praia da Bandeira (Ilha do Governador) foi descoberta por estudantes de Geologia (UFRJ) em 1972. Desde então, a ocorrência foi citada sem menção a sua localização por Menezes \& Klein (1973) e por Dalcolmo et al. (1981), em "fichas de descrição de afloramentos". Apesar de não possuir significado econômico, a ocorrência torna-se importante por estar alinhada, geograficamente, com outras evidências de magmatismo alcalino e, ainda, por ter sido parcialmente removida pela recente construção de um edificio na encosta onde aflorou.

\section{ROCHA ALCALINA DA ILHA DE JU. RUBAÍBA}

Alguns blocos de rocha alcalina foram encontrados na borda norte da tha de Jurubaiba, uma ilhota em forma de "oito" com quase $400 \mathrm{~m}$ de comprimento e $70 \mathrm{~m}$ de largura (Fig. 1), sob uma lâmina d'água de cerca de $1,5 \mathrm{~m}$ de profundidade. A pequena ilha integra um arquipélago com oito ilhas maiores, entre as quais se destaca $\mathrm{Pa}$ quetá, e ainda dezenas de penedos na parte leste da baia.

Essas ilhas são constituidas por granitos róseos, de granulação grossa até muito grossa, com megacristais centimétricos de microclina em matriz de quartzo e biotita (Granito Surui, Penha et al., 1980). De fato, tais ilhas constituem morros ou

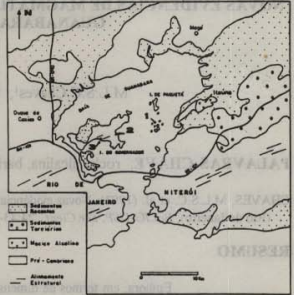

Figura 1 - Mapa geológico esquemático da regiăo da Baia de Guanabara (RJ), mostrando a localização da (1) Brecha alcalina próximo da tlha de Jurubaíba, (2) Ocorrência de barita da Praia da Bandeira, Itha do Governador e, (3) Calcedônia da Praia da Bica, na mesma ilha.

grandes matacø̃es isolados, unidos por faixas arenosas recentes.

Os blocos alcalinos de Jurubaiba são de uma brecha magmática de matriz fonolitica. Os blocos coletados, arredondados a sub-arredondados e de porte decimétrico, são de coloração cinza-claro. Não foi possível determinar a relação da brecha com os granitos que predominam na ilha.

A textura é brechóide, os componentes variando desde angulosos (predominantes) até sub-arredondados, de tamanhos submilimétricos a centimétricos e composições petrográficas distintas. A matriz, microcristalina, compõe-se de nefelina, feldspatóide do grupo da sodalita, aegerinaugita, microfenocristais de nefelina idiomórfica e zircão.

Microscopicamente, os fragmentos são de três tipos caracteristicos: (1) traquito, (2) nefelina fonolito e, (3) nefelina sienito 
(1) Traquito: a rocha possui textura porfiritica pouco grossa. Compóe-se de fenocristais de sanidina, albita e nefelina imersos em matriz principalmente alcali-feldspática. Ocorrem também, biotita (titanobiotita?), zircão e minerais opacos.

(2) Nefelina fonolito: possui textura granular fina, sendo composto de matriz com nefelina, aegerinaugita, óxidos de ferro e microfenocristais prismáticos de nefelina.

(3) Nefelina sienito: mostra textura porfiritica média a fina. A matriz é constituída por microcristais de aegerinaugita, nefelina, feldspatóide do grupo da sodalita, zircão e minerais opacos. Freqüentemente, são observados microfenocristais de nefelina, sanidina e pseudoleucita.

\section{BARITA NA ILHA DO GOVERNA- DOR}

A Illha do Governador é a maior das ilhas da Baia de Guanabara, situando-se em sua porção oeste. $\mathrm{O}$ veio mineralizado localiza-se no extremo norte da Praia da Bandeira, na parte leste da ilha, próximo à Ponta da Ostra (Fig. 1).

Nesta área afloram migmatitos diatexiticos atribuidos à Unidade Santo Aleixo (Dalcolmo et al., 1981). A atitude da xistosidade principal das rochas encaixantes é $\mathrm{N} 30^{\circ} \mathrm{W}, 40^{\circ} \mathrm{sW}$. Nas proximidades da ocorrência, os migmatitos estão fortemente intemperizados, deixando $\mathrm{em}$ destaque um veio de calcedônia brechada, ao qual se associa a barita.

$O$ veio de calcedônia, em relevo à beira-mar, adentra à Baia de Guanabara em direção aproximada NE-SW, com mergutho subvertical. No barranco que margeia a linha litorânea, observa-se o prolongamento do veio para o interior da ilha, parcialmente destruido.

$O$ veio possui aproximadamente 80 $\mathrm{cm}$ de espessura. Seu prolongamento em direção ao interior da ilha se marca por uma zona cataclástica brechosa rica em vênulas descontinuas de barita, com no máximo $5 \mathrm{~cm}$ de largura cada uma. As vênulas ocorrem por cerca de $10 \mathrm{~m}$ ao longo do veio. Nestas, a barita se apresenta em agregados de cristais sub-édricos e euédricos. Os primeiros podem alcançar quase $2 \mathrm{~cm}$, enquanto os cristais perfeitamente euédricos são diminutos, em geral menores que $5 \mathrm{~mm}$.

A coloração do corpo mineralizado da Praia da Bandeira é acastanhada nas porçôes externas e superficies de fraturas, devido à percolaçăo de material ferruginoso, sendo cor de creme ou caqui nas partes internas, pouco alteradas.

Um outro veio de calcedônia, também brechado, mas aparentemente sem mineralização de barita, foi observado na ponta oeste da Praia da Bica, na mesma ilha. Suas caracteristicas texturais e mineralógicas são muito semelhantes às do veio da Praia da Bandeira. Além disso, essa ocorrência encontra-se situada ao longo do mesmo alinhamento formado pelos corpos previamente descritos.

\section{ASPECTOS GENÉTICOS DAS OCOR- RÊNCLAS}

A brecha alcalina de Jurubaiba foi certamente formada em estágio magmático tardio, já que engloba fragmentos de rochas de composição distinta (incluindo componentes intrusivos e extrusivos) que thes são anteriores. Segundo Machado Filho et al. (1983), provavelmente, esta fase magmática é atribuida ao Terciário Inferior. Asmus \& Ferrari (1976) descreveram uma tectônica de blocos basculados em falhamentos de gravidade, de direção NE-SW, para explicar o magmatismo meso-cenozóico na região sudeste do Brasil (Fig. 2).

As ocorrências de barita no Estado do Rio de Janeiro, por sua vez, estão em intima associação às rochas alcalinas, con- 


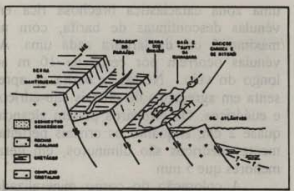

Figura 2 - Bloco diagrama na região costeira sudeste do Brasil (Estados de Minas Gerais e Rio de Janeiro), mostrando o rebaixamento de blocos $\mathrm{c}$ as ocorrências principais contendo produtos de magmatismo alcalino: (1) Maciço de Itaúna (Săo Goncalo), (2) Brecha da Ilha de Jurubaiba e, (3) Barita da Ilha do Governador (corte vertical modificado de Asmus \& Ferrari, 1976).

forme evidenciado nas ocorrências de Tribobó, Niterói (Abreu, 1960), Fazenda Taquari, Itaguaí (Menezes \& Klein, 1973) e do Maciço de Tanguá, Rio Bonito (Valença et al., 1974). A atividade hidrotermal tardia, causando silicificação, brechiação e mineralização nas rochas encaixantes, é comum em vários maciços alcalinos da área da Baía de Guanabara, podendo ser verificada mesmo à grande distância das intrusões, acompanhando os alinhamentos dados pelos falhamentos normais.

$\mathrm{Na}$ mesma direção das ocorrências estudadas aparecem, a nordeste, os complexos alcalinos de Itaúna e Tanguá. Em Tanguá, ocorrem também veios tardios mineralizados com barita, além de fluorita. Em Itaúna, também existem brechas magmáticas muito semelhantes às descritas (Valença, 1974; Machado Filho et al., 1983).

Os falhamentos normais a que se associam as atividades magmaticas alcalinas estão possivelmente relacionados à tectônica de separação América do Sul-África.

\section{CONSIDERAÇŌES FINAIS}

Provavelmente, a brecha da Ilha de Jurubaiba constitui o resquicio de material alcalino mais distante encontrado até agora, a sudoeste, a partir dos focos magmáticos maiores - Itaúna e Tanguá. Nesta mesma direção aparece, ainda mais afastada, a mineralização de barita e calcedônia da Ilha do Governador, correspondente à fase hidrotermal do emplacement das intrusōes citadas.

$\mathrm{Na}$ área da cidade do Rio de Janeiro, a oeste, apesar de persistirem os alinhamentos NE-SW, como simples direçōes de fraturamento (Fig. 1), não são conhecidas rochas ou produtos de manifestações alcalinas (Helmbold et al., 1965). Isto, pode indicar que o basculamento da falha ocorreu em direção nordeste (falha em tesoura), para onde aumentam as atividades relacionadas ao magmatismo.

Recentemente, Mohriak et al. (1990) enfatizaram a existência de intensa atividade magmática, incluindo alcalina, no Eoceno da plataforma continental do Estado do Rio de Janeiro. É provável, portanto, que a tectônica rúptil e o magmatismo alcalino associado sejam essencialmente de idade Terciária. Os maciços de Itaúna e Tanguá foram datados em $63 \mathrm{Ma}$. (Cordani \& Teixeira, 1979), idade máxima provável para a brecha da Ilha de Jurubaiba e do veio com barita da Ilha do Governador.

\section{AGRADECIMENTOS}

Um dos autores (MLSCC) expressa seus agradecimentos ao Prof. Dr. Jacques P. Cassedanne (UFRJ), pela leitura critica do manuscrito.

\section{REFERÊNCIAS BIBLIOGRÁFICAS}

ABREU, S.F. (1960) Recursos minerais do Brasil. Rio de Janeiro, Instituto $\mathrm{Na}$ cional de Tecnologia. 505p. 
ASMUS, H.E.; FERRARI, A.L. (1976) Hipótese sobre a causa do tectonismo cenozóico na região sudeste do Brasil. In: PROJETO REMAC: aspectos estruturais da margem continental leste e sudeste do Brasil. Rio de Janeiro, PETROBRÁS/CENPES/DINTEP. p. 77-87. (Projeto REMAC, 4).

CORDANI, U.G.; TEIXEIRA, W. (1979) Comentários sobre as determinações geocronológicas existentes para as regiōes das folhas Rio de Janeiro, Vitória e Iguape. In: SCHOBBENHAUS FILHO, C. (coord.) Carta geológica do Brasil ao milionésimo: Folha Rio de Janeiro (SF-23), Folha Vitória (SF-24), Folha Iguape (SG-23). Brasilia, DNPM. p. 175-207.

DALCOLMO, M.T.; FERRARI, A.L.; MELLO, E.F.; VAZ, M.A.A., BRENNER, T.L.; SILVA, V.P.; NASSAR, W.M. (1981) Projeto Carta Geológica do Estado do Rio de Janeiro: Bloco Baia Guanabara. Niterói, Departamento de Recursos Minerais, 404p. (Relatório Inédito)

DERBY, O.A. (1887) On nepheline rocks in Brazil, I, with special reference to the association of phonolite and foyaite. Quaterly Journal of the Geological Society of London, 43:457-473.

HELMBOLD, R; VALENÇA, J.G.C.; LEONARDOS, O.H; (1965) Mapa Geológico do Estado da Guanabara, Folhas Vila Militar e Baía de Guanabara. Rio de Janeiro, DNPM/DGM.

MACHADO FILHO, L.; RIBEIRO, M.W; GONZALES, S.R; SCHENINI, C.A. (1983) Geologia. In: PROJETO RADAMBRASIL. Folas SF-23/24 Rio de Janeiro/Vitória. Rio de Janeiro. DNPM/MME/SG. p. 27-304. (Levantamentos de Recursos Minerais, 32).

MARTINS, C.R.; BORGHI, G.S.N. (1982) Morro dos Gatos, foco de rochas alcalinas, Silva Jardim-Rio de Janeiro. Mineração e Metalurgia, (439): 18-20.

MENEZES, S.O; KLEIN, V.C. (1973) Ocorrências de barita em áreas adjacentes a maciços alcalinos no Estado do Rio de Janeiro. Mineração e Metalurgia, (345): 12-16.

MOHRIAK, W.U.; BARROS, A.Z.N.; FUIITA, A. (1990) Magmatismo e tectonismo cenozóico na região de Cabo Frio, RJ. In: CONGRESSO BRASILEIRO DE GEOLOGIA, 36., Natal, 1990. Anais. Natal, v.6, p. 2873-2885

PENHA, H.M.; FERRARI, A.L.; RIBEIRO, A.; AMADOR, E.S.; PENTAGNA, F; JUNHO, M.C.B.; BRENNER, T.L. (1980) A geologia da Folha Petropolis. In: CONGRESSO BRASILEIRO DE GEOLOGIA, 31., Balneário de Camboriú, 1980. Anais. Camboriú, SBG. v.5, p. 2965-2974

VALENÇA, J.G. (1974) Geologia e petrografia do maciço alcalino de Itaúna, São Gonçalo-Estado do Rio de Janeiro. In: CONGRESSO BRASILEIRO DE GEOLOGIA, 28., Porto Alegre, 1974. Resumo das Comunicaçóes. Porto Alegre, p. 427-431.

VALENÇA, J.G.; RIBEIRO, M.W.; REIS, A.P.; LIMA, P.R.A.S.; MACHADO FILHO, L.; GOMES, A.C.B. (1974) Ocorrências de fluorita no Municipio de Itaborai, RJ. Mineração e Metalurgia, (352): 8-10.

M.L.S.C.Chaves - Departamento de Geologia, UGC/UFMG - Av. Antônio Carlos, 6627 CEP $31.270-010$ Belo Horizonte, MG, Brasil. 